\title{
DIGITAL HUMAN SKILLS FORM THE CORPORATE ECONOMY AND BUSINESS DEVELOPMENT
}

\author{
Elena Malkawi ${ }^{1, \mathrm{a}, *}$ and Marina Khayrullina ${ }^{2, \mathrm{~b}}$ \\ ${ }^{1}$ CTL Eurocollege, 118 Spyros Kyprianou Ave., 3077 Limassol, Cyprus \\ ${ }^{2}$ Novosibirsk State Technical University, 20 Karl Marks Pr., 630073 Novosibirsk, Russia \\ aelenamalkawi@ rocketmail.com, ${ }^{b}$ khayrukkina@corp.nstu.ru \\ ${ }^{*}$ Corresponding author
}

Cite as: Malkawi, E., Khayrullina, M. (2021). Digital human skills from the corporate economy and business development. Ekonomicko-manazerske spektrum, 15(1), 64-74.

Available at: dx.doi.org/10.26552/ems.2021.1.64-74

Received: 8 January 2021; Received in revised form: 12 April 2021; Accepted: 20 April 2021; Available online: 28 April 2021

\begin{abstract}
Digitalization, intensified by the COVID-19 pandemic, presents great opportunities for economic growth and development of businesses. At the same time, it brings challenges such as new requirements for human skills. To facilitate digital transition in the corporate sector and obtain its benefits, there is high demand for people skilled in the existing digital technologies and able to adapt to changes quickly. Digital transformation demands lifelong learning and reinforces the link between education, training, and work. Educators and other professionals in the field need to adjust to being "twenty-first century educators" and to consider a range of new digital skills that will allow students to develop a variety of professional and personal abilities. To examine human skills required by digitalization, this study set out to investigate elements of an existing digital learning environment in a university based on feedback from its 2020 spring term students. The research is grounded in a social cognitive perspective of self-regulation and in recent contributions from the multidisciplinary humancomputer interaction (HCI) field. The data came from the total of 2,347 university students, was collected through an online survey, evaluated using the SPSS software, and qualitatively analyzed. The study revealed that students pinpointed three groups of problems in online learning: the process of concentration and self-regulation; the process of getting feedback from tutors and peers; and technical difficulties with staying connected. The researchers attempted to shed light on self-regulation as an essential human skill that is required for successful business and corporate development in the digitalized environment.
\end{abstract}

Keywords: skills; technology and employment; human development; social innovation; selfregulation

JEL Classification: I25; J24; O15; O33; O35

\section{Introduction}

Digitalization presents a variety of great opportunities for economic growth and development of businesses. At the same time, it brings challenges such as new requirements for human skills. In pursuit of digital transformation, a firm's redefinition of how it creates and delivers value to customers often requires it to access, acquire, or develop new digital assets 
and capabilities (Verhoef et al., 2021). Ongoing digital innovations are transforming almost every aspect of our contemporary societies - rendering our lives and work ever more fluid and dynamic (Mousavi et al., 2021). Businesses today are embracing technology at a rapid pace and creating a pool of new jobs; thus, there is a paradigm shift in the skill set required (Koul and Nayar, 2020). To facilitate digital transition and obtain its benefits, there is high demand for people skilled in the existing digital technologies and quick to adapt to digital innovations. In a world where the task content of jobs is progressively de-routinised and changing faster than ever, adaptability, communication, collaboration skills, critical thinking, creativity, entrepreneurship, and readiness to learn become all the more important (Morandini et al, 2020). In 2020, the COVID-19 pandemic shook up the landscape of economies worldwide and drastically stimulated digital transformation. Since then, we have witnessed an unprecedented acceleration in adoption of new technologies and digital channels for interacting with customers (Guenzi and Nijssen, 2021). Employees and employers had to rapidly adjust to virtual communication, universities shifted to online teaching, and new technologies adopted to provide care from afar (Gibson, 2020).

Now researchers should ask questions that seek to better understand the processual aspects and personal outcomes of the professional journey in a pandemic-changed workplace (Hoff, 2021). Digital transformation demands lifelong learning and reinforces the link between education, training, and work. In order to respond to market demands of a competitive work force, younger generations need to gain skills and competences to innovate, design, program, make, and build digital technology (Iivari et al., 2020). The most recent research in the area of higher education examines students' and teachers' perceptions regarding the ability of universities to provide knowledge in the context of digital transformation (Coman et al., 2020; Iglesias-Pradas et al., 2021; Scherer et al., 2021).

The importance of technology in the education system, be it online or offline, cannot be underestimated, but at the same time, we cannot ignore the fact that the usage of e-learning tools in online education largely depends on the instructors' and students' characteristics (Baber, 2021). Educators and other professionals in the field of education need to adjust to being twenty-first century educators and to consider a range of new digital skills that will allow students to develop a variety of professional and personal abilities.

This research explores feedback from 2,347 students who took online courses in the 2020 spring term at the Novosibirsk State Technical University (NSTU) which offered about one hundred courses in technical, economic, and humanitarian fields from undergraduate to postdoctoral level.

\section{Research methodology}

The research consisted of two phases. Phase One included questionnaire surveys to explore students' attitudes towards technology and any negative experiences they had in the online learning process of the 2020 spring term. Phase Two aimed to examine the theoretical background and best practices in problematic areas (explored throughout Phase One) in order to formulate recommendations to improve the quality of higher education in a digital society.

Phase One tools included an online questionnaire survey which was filled in by 2,347 university students. The survey gauged the participants' demographics as well as their opinions regarding learning problems related to the design of online courses in spring 2020 (fifteen multiple-choice questions and one open-end question); opinions regarding learning efficiency 
and course design (eleven multiple-choice questions) and attitude towards technology (with a five-point Likert scale, fifteen questions). The average time taken to answer the questions was about twenty minutes. Phase Two consists of a review of the existing learning theories and their practical applications in digital learning environment.

The researchers performed quantitative and qualitative analyses. Statistical analysis was done with the use of the SPSS software. First, the normality of the data from each section of the questionnaire was tested by calculating the values of skewness and kurtosis. It is commonly accepted that data are normally distributed when skewness and kurtosis are respectively within the range of \pm 1 and \pm 3 (Tabachnick and Fidell, 2013). The results revealed that the distribution of the all the data was close to a normal distribution.

The statistics employed for the analysis of the scale of reliability of the questionnaire was Cronbach's alpha. The initial reliabilities of the variables were 0.803 and 0.801 , respectively, which indicates good internal consistency. Additionally, content validity was assessed by carefully checking the measurement methods against the concept of effective course design. To ensure the validity and reliability of the construct, researchers performed factor analysis on the responses to the questions about attitudes toward technology. Only the items with strong factor loadings higher than 0.5 were used for analysis purpose.

Qualitative descriptive analysis was used to understand and summarize specific experiences of students (Silverman, 2017). The themes of participants' answers to the open-ended question were generated and described by coding the text data, developing a description, and defining main themes from the data. The coding was mainly completed by the first author, while the second author checked and reviewed the codes and themes to ensure that the coding processes were consistent, and the data matched the codes and themes that had been set.

The purpose of the survey was to investigate university students' recent experience in online learning. It was administered to all 11,517 students of the NSTU as a convenient sample, twenty percent of whom participated. Out of the participants, forty percent were female and sixty percent were male, with the majority (ninety-seven percent) between seventeen and twenty-five years of age (weighted mean of twenty years of age). Forty-two percent of participants were master's degree students and twenty percent bachelor's degree students.

\section{Data analysis and results}

The technology acceptance model (TAM) is one of the primary theories applied by existing studies to students' attitudes towards online courses. This model examines students' willingness to use technology based on their perceptions of ease of use and usefulness. Students who are less willing to accept technology are more likely to report negative experiences with online learning. The present research used a survey to find out students' attitudes toward technology (Appendix 1). The results of the survey at 3.38 points out of 5.00 (Likert scale) revealed that participants on the whole appreciate and accept technology. Consequently, their personal attitudes towards technology are not likely to have negative influence on their perceptions of the online learning process.

Moreover, only about thirty percent of participants had previous experience with online education platforms like Coursera, edX, Stepik, while forty-six percent of participants stated that they prefer to substitute some of their offline courses with online courses. This illustrates a positive dynamic in students' opinions regarding online learning experience. The analyzed students' opinions about design of online courses, listed in Table 1, support the said statement, as forty-nine percent of participants noted that "the mode of study (online/F2F) is not important 
as long as it serves the purpose of study" and only twelve percent of participant stated that "the best way to study in university is F2F".

Table 1: Students' opinions regarding learning design in university

\begin{tabular}{ll}
\hline & \% \\
\hline Mode of study (online/F2F) is not important as long as it serves the purpose of study & 49.0 \\
It is very important to have open communicational channel with the tutor and peers for effective & 25.7 \\
learning & 12.2 \\
The best way to study in university is F2F & 8.6 \\
It is very important to involve into research while studying the course & 4.5 \\
I don't know & 100 \\
TOTAL & \\
\hline
\end{tabular}

Source: Authors, based on Han et al (2020)

In general, fifty-six percent of participants reported no learning problems when taking courses online, while 1,039 students (forty-four percent) acknowledged various types of problems caused by design of the online courses. Difficulty points are allocated in descending order in Table 2 according to frequencies of their being mentioned by students. The most frequent difficulty that students were faced with was related to self-regulation of the online learning process, while the least frequent complaint is related to the technical devices needed to study online.

Table 2: Difficulty points in online learning process

\begin{tabular}{llll}
\hline & I found difficult to: & $\begin{array}{l}\text { Number of } \\
\text { answers }\end{array}$ & Frequency, \% \\
\hline 1 & Manage my self-study process & 1039 & 100.00 \\
2 & Study at home & 987 & 95.00 \\
3 & Get feedback from tutor & 979 & 94.23 \\
4 & Have a discussion with the tutor & 907 & 87.30 \\
5 & Provide and justify my points of view to instructors & 819 & 78.83 \\
6 & Manage technical issues & 774 & 74.49 \\
7 & Communicate with peers & 711 & 68.43 \\
8 & Remain focused during video lessons & 538 & 51.78 \\
9 & Feel connected to society while staying mostly online & 491 & 47.26 \\
10 & Have a group discussion regarding a subject & 469 & 45.14 \\
11 & Find a suitable place to study at home & 360 & 34.65 \\
12 & Use a web camera at home & 292 & 28.10 \\
13 & Get familiar with UI of online learning applications & 225 & 21.66 \\
14 & Have a suitable devise or internet connection to study online & 124 & 11.93 \\
15 & Other & 94 & 9.05 \\
& Total number of students who answered this part of survey & 1039 & 100 \\
\hline
\end{tabular}

Source: Authors, Based on Silverman (2017)

Statements listed above were presented to participants as multiple-choice questions. In the open-ended section of the survey, the participants were asked to describe the problems they had been faced with in detail. Two hundred and eighty-six students answered the open-ended question. An analysis of the main themes of their answers can be found in the Table 3 below, where items are grouped according to the identified points of difficulty, together with the items from the multiple-choice section. Quantitative results of the survey and qualitative analysis of the quotes revealed a following list of negative experiences that students had in the online learning process: (1) insufficient level of self-regulating and technical skills of the student; (2) poorly established process of communication with tutors and peers; (3) self-isolation at home where it is difficult to create a learning environment; (4) insufficient tutors' online teaching skills. 
Regarding the problems related to self-isolation at home (group 3), there is not much that could be done by universities. The remaining groups of problems could be managed in two directions. One of them is to develop digital skills of students and academic staff, the other to establish an appropriate level of connectivity. Problems with connectivity in online learning design were discussed in detail in our previous publication (Malkawi and Khairullina, 2021). The present paper focuses on the digital skills needed for efficient and effective performance in digitalized learning environment.

Table 3: Negative experiences that students had in the online learning process

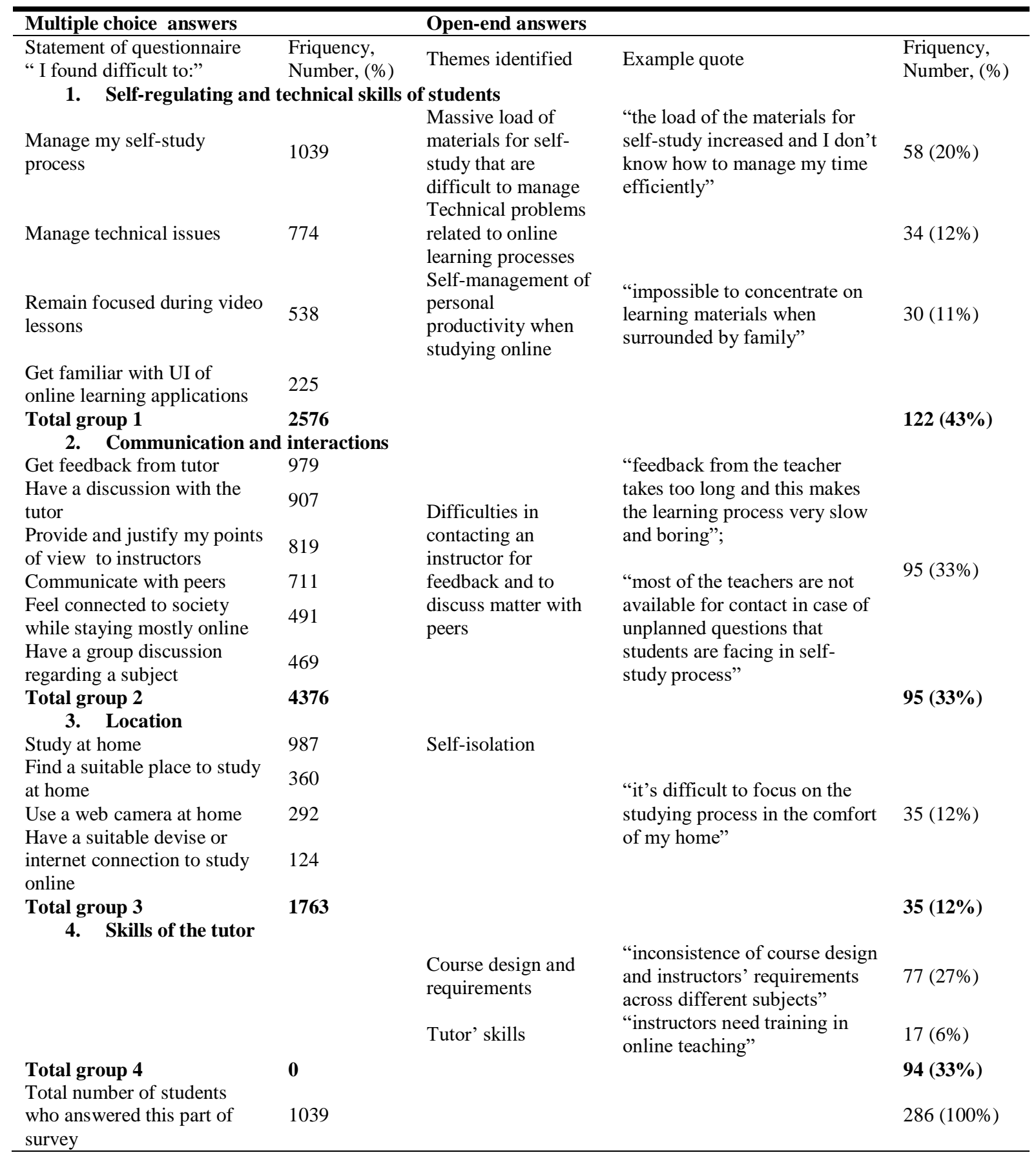




\section{Discussion}

Firstly, research reveals that the students found it difficult to focus their attention on learning materials when surrounded by online distractions. A person working on an information-related task can be easily distracted by other activities, such as checking e-mails or surfing the web. A massive volume of functionality that is readily available often makes it difficult for the users of information communication technologies (ICTs) to focus on their current task and avoid being distracted by notifications or habitual check-ins (Thomas et al., 2016). While information technology provides a vast number of benefits, a growing amount of research attention focuses on the visible disadvantages (Wu, 2016; Alter, 2017; Tiku, 2018). Specifically, a recent movement in human-computer interactions $(\mathrm{HCI})$ research has called to examine an intentional 'non-use' of ICTs (Hiniker et al., 2016). A substantial body of related research has now recognized that a majority of users feel conflicted about the time they spend with internetconnected digital technologies and struggle with effective self-control (Sleeper et al., 2015; Ko et al., 2016; Lyngs et al., 2019). Connectivity provided by technology poses a constant dilemma of time and attention allocation among work and nonwork demands because they create extrinsic pressure to be aware of work while engaging in nonwork activities. Research suggests that in reality, "flexible work boundaries" often turn into "work without boundaries", compromising employees' and their families' health and well-being (Becker et al., 2021).

Secondly, students have reported that they do not know how to manage increased workloads and their time efficiently, as well as being unaware of how to take advantage of the technology available for information management and self-regulated learning. Related research that investigates whether university students do in fact use digital technologies to plan, organize, and facilitate their own learning shows that students are not inclined to use technologies when regulating their own learning process, even when they are regular users of digital technologies for social, personal, and leisure activities, among others (Yot-Domínguez and Marcelo, 2017). This can be partly explained by students' limited awareness of how to apply familiar technologies to the learning process. Although ICTs are omnipresent at work and in education, not all employees and students have the skills necessary to take advantage of this in terms of the richness of activities and the variety of learning opportunities ICTs offer (Van Laara et al., 2019). Although students know how to use technologies, they are lacking in ability to use them efficiently to support their own learning process. For example, social networks have a low level of use for learning because they are not perceived as a tool with a high educational potential (Swanson and Walker, 2015).

Consequently, focusing on a self-regulation concept is necessary when preparing students to gain the experience, skills, and knowledge to succeed in the 21 st century. An online learning environment demands more from students' self-regulation skills (Boor and Cornelisse, 2021). Self-regulation and time management as well as past online learning experience are additional factors that have been shown to be related to satisfaction with and usefulness of online learning (Landrum, 2020). Self-regulating learners maintain an active and ongoing awareness of task demands, the effectiveness of learning strategies, and their progress toward task completion (Van Laar et al., 2019). Self-control processes help individuals to concentrate on the task and to optimize their efforts (Senkbeil and Ihme, 2017).

A social cognitive perspective describes self-regulation as an interaction of personal, behavioral, and environmental triadic processes (Bandura, 1991). More specifically, it requires 
not only behavioral skills, but also the knowledge and personal involvement to use these skills in relevant contexts. Self-regulation refers to self-generated thoughts, feelings, and actions that are planned and cyclically adapted to attainment of personal goals (Zimmerman, 2000). This definition can explain why a person may self-regulate one type of performance but not another, or why students found it difficult to self-regulate their online performance and did not find it difficult to self-regulate with respect to other activities.

Self-regulation is defined as cyclical because feedback from previous performances is used to adjust present performance. Such adjustments are necessary because personal, behavioral, and environmental factors are constantly changing during the course of learning and performance, and consequently the changes must be observed (Zimmerman, 2000). This refers to an individual's tracking of specific aspects of their own performance, the conditions that surround it, and the effects that it produces (Zimmerman and Paulsen, 1995).

Self-regulatory techniques such as goal setting and strategic planning present any value only when a person is able to motivate themselves to use them. Effective self-regulatory processes are composite and require anticipation, concentration, effort, and careful self-reflection. Because of their complexity, self-regulatory processes are used only when a skill or its outcomes are highly valued. When the skill or its outcomes are not perceived as valuable, there is no incentive to self-regulate (Zimmerman and Schunk, 2011). There are a number of key self-motivational beliefs: self-efficacy, outcome expectations, intrinsic interest or valuing, and goal orientation. During the self-regulation process, methods of self-control, such as selfinstruction, imagery, attention focusing, and task strategies, help learners to focus on the task and optimize their effort.

From a social cognitive perspective, dysfunctions in self-regulation are mostly due to ineffective planning and tracking of self-performance (Bandura, 1991; Zimmerman, 1998). Significant sources of self-regulation problems are an absence of social learning experiences and lack of motivation, for example apathy or disinterest. Research results (Yot-Domínguez and Marcelo, 2017) show a profile of a university student who usually fails to consider it necessary, or lacks the adequate training, to incorporate digital technologies into their own academic learning process. Particularly with technologies, students make limited use of selfregulation strategies because they perceive that the digital technologies they use have more to do with simple activities such as searching, storing, or sharing information. These activities, although necessary for the learning process, are limited when not complemented with others that support understanding, monitoring, or self-assessment of the actual student throughout the learning process (Yot-Domínguez and Marcelo, 2017).

A very important aspect of self-regulation is the relation of this concept to human digital skills of the twenty-first century. In a systematic literature review paper (Van Laar et al., 2017) twenty-first century digital skills of knowledge workers are synthesized and conceptualized, and the following skills were identified: information, communication, collaboration, critical thinking, creativity, and problem-solving skills. These skills are generic skills with specific importance in digital contexts (Kereluik at el., 2013). Several studies show that people vary greatly with regard to their digital skill levels (Van Deursen and Van Dijk, 2015; Verhoeven at el., 2016). Research that aims to explain differences in the level of various twenty-first century digital skills by examining potential personal, motivational, and social determinants at the level of the individual worker found that self-regulation contributes positively to information management, communication expressiveness, and creativity (Van Laar et al., 2019). This means that an effective self-regulation process can be a determinant of successful performance when people use information and communication technologies to access and disseminate information, to interact and exchange experiences with experts and learning communities, and to generate 
and refine their ideas. This determinant can be, up to a certain level, developed by ICT users themselves, as well as promoted and influenced by policy makers and educators.

\section{Recommendations}

We can define two parallel ways to promote the development of self-regulation with regard to twenty-first century digital skills.

The first of these is teaching and training of educational instructors about the role of selfregulation in successful performance in the digital environment. As Boor and Cornelisse stated: "In order to achieve effective learning in an online environment, we argue that increasing students' self-regulatory skills must be a central tenet in designing online education" (Boor and Cornelisse, 2021). Teachers need to recognize and account for different types of learners and encourage and scaffold students' effective use of self-regulation strategies (Alt and NaamatiSchneider, 2021). Even students with a high degree of digital competencies need information about how to use digital technologies that favor their own learning and support, advice and motivation from teachers becomes crucial. Although it is possible to develop self-regulatory competence by personal discovery, this path is often tedious, frustrating, and limited in its effectiveness. Fortunately, self-regulatory processes can be acquired from and are sustained by social as well as self-sources of influence (Zimmerman and Schunk, 2011).

Most important motoric or cognitive task skills are originally acquired by observing, reading, or hearing about the performance of skilled models, such as parents, teachers, coaches, or peers with expertise. Later, socially transported skills become self-regulated. According to a social cognitive perspective, the acquisition of a wide range of task competencies, from personal care skills to academic learning strategies, emerge in a series of regulatory skill levels:

Level 1 Observation: Vicarious induction of a skill from a proficient model.

Level 2 Emulation: Imitative performance of the general pattern or style of a model's skill with social assistance.

Level 3 Self-control: Independent display of the model's skill under structured condition.

Level 4 Self-regulation: Adaptive use of skill across changing personal and environmental conditions.

A self-regulated level of a task skill is achieved when learners can systematically adapt their performance to changing personal and contextual conditions. At this fourth level of skill, the learner can vary the use of task strategies and make adjustments based on outcomes (Zimmerman, 2000). University teachers must favor self-regulation of learning and offer the students opportunities to discover the usefulness of digital technologies and foster their incorporation into the actual learning process (Yot-Domínguez and Marcelo, 2017).

The second direction that will help to improve human digital skills with the use of selfregulation is practical application of recent contributions from the multidisciplinary humancomputer interaction field. Currently the challenge of supporting self-regulation and selfcontrol over online disruptions has become widely discussed and a growing number of studies have developed and evaluated new design interventions. Researchers within HCI have started to design, implement, and test new tools for supporting self-control over online distractions.

Some of these tools are using interventions such as gamification and social sharing of total time spent on one's smartphone (Ko et al., 2016) or visualization of laptop use (Whittaker et al., 2016), and some of these 'digital self-control tools' have gathered millions of users. For example, Forest (Seekrtech, 2018) is a piece of software which encourages users to develop 
self-control through growing virtual trees. As a theoretical lens to organize and evaluate new tools and provide a deeper understanding of self-control challenges in cyberspace, a recent research (Lyngs et al, 2019) reviewed 367 apps and browser extensions for digital self-control from the Google Play, Chrome Web, and Apple App stores, and identified common design features and strategies. Another research founded on self-regulation theory argues that the characteristics of music (i.e., musical key, tempo, complexity, volume) influence job performance through cognitive self-regulatory processes and describe implications for organizations with regard to allowing or even encouraging employees to listen to music at work (Keeler, 2020).

Although understanding of how to best approach the challenge of self-control in cyberspace remains limited (Cox et al., 2016; Whittaker et al., 2016; Mark et al., 2018), future research directions in HCI fields aim toward clarification of how specific design features may work to support successful self-control.

\section{Conclusion}

The digital transformation of economy demands lifelong learning and reinforces the link between education, training, and work. Living in a digitalized connected world changes the dynamic of the learning process and reshapes human skills that are required by the digital twenty-first century. The researchers attempted to investigate elements of an existing digital learning environment in a university. Insufficient level of ICT self-regulation, reported by students, is explained by difficulties to focus when surrounded by online disruptions, and by inadequate knowledge of technology available for information management and self-regulated learning. These issues can be addressed by understanding the concept of self-regulation online and by promoting different tools to stimulate self-regulated learning. Self-regulation is key to many human digital skills of the twenty-first century that will allow students to develop a variety of professional and personal abilities demanded by the digital economy and corporate development.

\section{Appendix}

\begin{tabular}{lll}
\hline & & From 1 to 5 \\
\hline 1 & Technology helps me to control my daily routine & 3.83 \\
2 & Technology improves the quality of my life & 4.05 \\
3 & Technology provides my mobility & 3.71 \\
4 & Technology improves my productivity & 3.64 \\
5 & I am able to learn new technology independently/without external support & 3.26 \\
6 & Among my friends I am a first person to use new technology & 2.66 \\
7 & I am constantly monitoring technological developments in areas of my interests & 3.18 \\
8 & When I receive technical support I feel unsecured, because they know more than I do & 3.04 \\
9 & I hardly can understand comments of technical support staff & 3.71 \\
10 & Seems to me, new technology can't be used by ordinary person & 3.71 \\
11 & I never find it easy to understand user' manual for technological products & 3.58 \\
12 & People unnecessarily depend on technology that replacing human skills & 2.67 \\
13 & Variable technological tools distracting people and it is harmful for society & 3.19 \\
14 & Technology is badly affecting the way people communicate and interact & 3.19 \\
15 & When I communicate with organization that available online only, I feel unsecured & 3.22 \\
& MEAN & $\mathbf{3 . 3 8}$ \\
\hline
\end{tabular}

Source: Authors, based on Al-Emran et al. (2018) 


\section{Acknowledgment}

The authors would like to thank the Centre of Information of Novosibirsk State Technical University for their valuable contribution to the process of data collection.

\section{References}

Al-Emran, M., Mezhuyev, V., \& Kamaludin, A. (2018). Technology acceptance model in m-learning context: A systematic review. Computers \& Education, 125, 389-412.

Alt, D., \& Naamati-Schneider, L. (2021). Health management students' self-regulation and digital concept mapping in online learning environments. BMC Medical Education, 21(1), 110.

Alter, A. (2017). Irresistible: The Rise of Addictive Technology and the Business of Keeping Us Hooked. Penguin Press.

Baber, H. (2021). Modelling the acceptance of e-learning during the pandemic of COVID-19-A study of South Korea. The International Journal of Management Education, 19, 1-15.

Bandura, A. (1991). Self-regulation of motivation through anticipatory and self-reactive mechanisms. In R. A. Dienstbier (Ed.), Nebraska Symposium on Motivation: Lincoln: University of Nebraska Press, 38, 69-164.

Becker, W. J., Belkin, L. Y., Conroy, S. A., \& Tuskey, S. (2021). Killing me softly: Organizational e-mail monitoring expectations' impact on employee and significant other well-being. Journal of Management, 47 (4), 1024-1052.

Boor, I. \& Cornelisse, S. (2021). How to encourage online self-regulation of students. Communications of the Association for Information Systems, 48, 211-217.

Coman, C., Tîru, L. G., Mesesan-Schmitz, L., Stanciu, C., \& Bularca, M. C. (2020). Online teaching and learning in higher education during the coronavirus pandemic: Students' perspective. Sustainability, 12, 1-24.

Cox, A. L, Gould, S. J. J., Cecchinato, M. E., Iacovides, I., \& Renfree, I. (2016). Design frictions for mindful interactions: the case for microboundaries. Proceedings of the 2016 Chi Conference Extended Abstracts on Human Factors in Computing Systems, 1389-97.

Gibson, C. (2020). From 'social distancing' to 'care in connecting': An emerging organizational research agenda for turbulent times. Academy of Management Discoveries, 6.

Guenzi, P., \& Nijssen, E. J. (2021). The impact of digital transformation on salespeople: An empirical investigation using the JD-R model. Journal of Personal Selling \& Sales Management, 1-20.

Han, F., Pardo, A., \& Ellis, R. A. (2020). Students' self-report and observed learning orientations in blended university course design: How are they related to each other and to academic performance? Journal of Computer Assisted Learning, 36(6), 969-980.

Hiniker, A., Sungsoo, R. H., Tadayoshi, K., \& Kientz, J. A. (2016). MyTime: Designing and evaluating an intervention for smartphone non-use. Proceedings of the 2016 CHI Conference on Human Factors in Computing Systems, 4746-57.

Hoff, T. (2021). Covid-19 and the study of professionals and professional work. Journal of Management Studies, $1-5$.

Iglesias-Pradas, S., Hern'andez-García, A., Chaparro-Pel'aez, J., \& Prieto, J.L. (2021). Emergency remote teaching and students' academic performance in higher education during the COVID-19 pandemic: A case study. Computers in Human Behavior, 119, 1-18.

Iivari, N., Sharma, S., \& Vent"a-Olkkonen, L. (2020). Digital transformation of everyday life - how COVID-19 pandemic transformed the basic education of the young generation and why information management research should care? International Journal of Information Management, 55, 1-6.

Keeler, K. R., \& Cortina, J. M. (2020). Working to the beat: A self-regulatory framework linking music characteristics to job performance. Academy of Management Review, 45(2).

Kereluik, K., Mishra, P., Fahnoe, C., \& Terry, L. (2013). What knowledge is of most worth: Teacher knowledge for 21st century learning. Journal of Digital Learning in Teacher Education, 29(4), 127-140.

Ko, M., Seungwoo C., Koji Y., \& Uichin L. (2016). Lock N' LoL: Group-based limiting assistance app to mitigate smartphone distractions in group activities. Proceedings of the 2016 Chi Conference on Human Factors in Computing Systems, 998-1010.

Koul, S., \& Nayar, B. (2020). The holistic learning educational ecosystem: A classroom 4.0 perspective. Higher Education Quarterly, 98-112.

Landrum, B. (2020). Examining students' confidence to learn online, self-regulation skills and perceptions of satisfaction and usefulness of online classes. Online Learning, 24(3), 128-146. 
Lyngs, U., Lukoff, K., Slovak, P., Binns, R., Slack, A., Inzlicht, M., Van Kleek, M., \& Shadbolt, N. (2019). Selfcontrol in cyberspace: Applying dual systems theory to a review of digital self-control tools. Conference on Human Factors in Computing Systems Proceedings (CHI 2019), 4-9.

Malkawi E., \& Khayrullina, M. (2021). Digital learning environment in higher education: New global issues. $S H S$ Web of Conferences, 92.

Mark, G., Czerwinski, M., \& Iqbal, S. T. (2018). Effects of Individual Differences in Blocking Workplace distractions. Proceedings of the 2018 Chi Conference on Human Factors in Computing Systems, 92, 1-12.

Morandini, M. C., Thum-Thysen, A., \& Vandeplas A. (2020). Facing the digital transformation: Are digital skills enough? European Economy. Economic Briefs, 054.

Mousavi, B. R., Introna, L. D., \& Hultin, L. (2021). Everything flows: Studying continuous sociotechnological transformation in a fluid and dynamic digital world. MIS Quarterly, 45(1), 423-452.

Scherer, R., Howard, S. K., Tondeur, J., \& Siddiq, F. (2021). Profiling teachers' readiness for online teaching and learning in higher education: Who's ready? Computers in Human Behavior, 118, 1-16.

Seekrtech (2018). “Forest: Stay focused.” https://www.forestapp.cc.

Senkbeil, M., \& Ihme, J. M. (2017). Motivational factors predicting ICT literacy: First evidence on the structure of an ICT motivation inventory. Computers \& Education, 108, 145-158.

Silverman, D. (2017). Doing qualitative research. California: SAGE Publications.

Sleeper, S., Acquisti, A., Cranor, L. F., Kelley, P. G., Munson, S. A., \& Sadeh, N. (2015). I would like to..., I shouldn't..., I wish I.. Proceedings of the 18th ACM Conference on Computer Supported Cooperative Work \& Social Computing - CSCW (15), 1058-69.

Swanson, J. A., \& Walker, E. (2015). Academic versus non-academic emerging adult college student technology use. Technology, Knowledge and Learning, 20(2), 147-158.

Tabachnick, B. G., Fidell, L. S. (2013). Using multivariate statistics. Boston: Pearson Education.

Thomas, V., Azmitia, M., \& Whittaker, S. (2016). Unplugged: Exploring the costs and benefits of constant connection. Computers in Human Behavior, 63, 540-48.

Tiku, N. (2018). The WIRED Guide to Internet Addiction. https://www.wired.com/story/wired-guide-to-internetaddiction/.

Van Deursen, A. J. A. M., \& Van Dijk, J. A. G. M. (2015). Internet skill levels increase, but gaps widen: A longitudinal cross-sectional analysis (2010-2013) among the Dutch population. Information, Communication \& Society, 18(7), 782-797.

Van Laar, E., Van Deursen, A. J. A. M., Van Dijk, J. A. G. M., \& De Haan, J. (2017). The relation between 21stcentury skills and digital skills: A systematic literature review. Computers in Human Behavior, 72, 577-588.

Van Laara, E., Van Deursena, A. J. A. M., Van Dijka, Jan A. G. M., \& De Haan, J. (2019). Determinants of 21stcentury digital skills: A large-scale survey among working professionals. Computers in Human Behavior, 100 (2019), 93-104.

Verhoef, P. C., Broekhuizen T, Bart Y, et al. (2021). Digital transformation: A multidisciplinary reflection and research agenda. Journal of Business Research, 122, 889-901.

Verhoeven, J. C., Heerwegh, D., \& De Wit, K. (2016). ICT learning experience and research orientation as predictors of ICT skills and the ICT use of university students. Education and Information Technologies, 21(1), 71-103.

Whittaker, S., Kalnikaite, V., Hollis, V., Andrew Guydish, A. (2016). Don’ t waste my time: Use of time information improves focus. Proceedings of the 2016 Chi Conference on Human Factors in Computing Systems, 1729-38. New York: ACM.

Wu, T. (2016). The Attention Merchants: The Epic Scramble to Get Inside Our Heads. Knopf Publishing Group.

Yot-Domínguez, C., \& Marcelo, C. (2017). University students' self-regulated learning using digital technologies. International Journal of Educational Technology in Higher Education (2017), 14-38.

Zimmerman, B. J. (1998). Developing self-fulfilling cycles of academic regulation: An analysis of exemplary instructional models. D. H. Schunk \& B. J. Zimmerman (Eds.), Self-regulated learning: From teaching to selfreflective practice, New York: Guilford.

Zimmerman, B. J., \& Paulsen, A. S. (1995). Self-monitoring during collegiate studying: An invaluable tool for academic self-regulation. P. Pintrich (Ed.), New directions in college teaching and learning: Understanding self-regulated learning, San Francisco, CA: Jossey-Bass.

Zimmerman, B. J., \& Schunk, D. H. (2011). Self-regulated learning and performance. B. J. Zimmerman, \& D. H. Schunk (Eds.), Handbook of self-regulation of learning and performance, New York: Routledge.

Zimmerman, B. J. (2000). Attainment of self-regulation: A social cognitive perspective. Boekaerts, M., Pintrich, P. R. and Zeidner, M., Eds., Handbook of Self-Regulation, Academic Press, San Diego. 